\title{
The First Principle Approach in Estimating Bulk Modulus Based on Explicit Expression of Canonical Partition Function
}

\author{
${ }^{1}$ University of Neyshabur, Neyshabur, Razavi Khorasan Province, Iran, e-mail: Hojiat.mangeli67@gmail.com \\ ${ }^{2}$ Farhangian University, Bojnord, North Khorason Province, Iran, e-mail: Haghighi.behzad@gmail.com
}

\begin{abstract}
The bulk modulus is one of the most important characteristic features of solids. Accordingly, it have been developed a statistical-mechanical treatment based on an equation which allows to calculate the bulk modulus for solids with the minimum manifold of input data. In our model, a conjunction between Gruneisen parameter and canonical partition function has been established. We have found out that the volume dependency of Gruneisen parameter is critical in estimating bulk modulus. The result for hexagonal closed-packed (hcp) iron is very good and commensurate with the best measurements. This framework can be extended to the other elemental solids or a variety of compounds.
\end{abstract}

Keywords: bulk modulus, canonical partition function, density, Gruneisen parameter, statistical mechanics.

Received 25.01.2020, accepted for publication 15.03.2020.

\section{Introduction}

Nowadays, it is desirable for molecular physicists to estimate, predict and calculate thermophysical properties of matter [1-10]. These methods are more efficient and cost effectively in respect to experimental procedures.

Indeed, ability to understand fundamental equations of thermodynamics on purely molecular level, using nothing other than the above information and the tools of equilibrium statistical mechanics, has been a challenge since over a century ago and is still an open problem in the research frontiers of the present era. That is why, these approaches have attracted the attention of physicists [11-13].

Moreover, thermodynamic systems are described by macroscopic parameters, such as density, elasticity, temperature, entropy, and others [14]. These parameters, which define adequately the state of such systems, are uniquely connected by various relations, so that thermodynamics like mechanics is a dynamic theory ${ }^{15}$. In those cases when the thermodynamic relations do not satisfy our requirements and we wish to establish the properties of a many-particle system by starting from the properties of the particles themselves, we must turn to the molecular theory of these systems, i.e., to statistical physics [11-13, 16-17].

Furthermore, bulk modulus is an important physical quantity, characterizing the an-harmonic dynamic properties $^{18}$ under the effect of pressure [19-20]. Additionally, bulk modulus, which is defined as the inversion of isothermal compressibility factor, is critical for understanding thermodynamics and thermo-elastics behavior of solids at high temperatures [21-22]. Henceforth, reliable estimation of aforesaid property is important in solid state sciences [23].

The experimental determination of bulk modulus for solids at high temperature is extremely difficult. Also, accurate data are often scarce or non-existent in these conditions. It is, therefore, desirable to develop an analytical model from first principles to predict bulk modulus in those areas where no experimental data are available. It should also be mentioned that the development of an analytical model for predicting bulk modulus prevents most of the serious errors in the calculations of thermodynamics functions which arise from the uncertainty of bulk modulus at high pressures. Therefore, toward the eventual goal of a fundamental and unambiguous methodology of the microscopic thermodynamics, the objective of the present paper is to develop microscopic recipe based on statistical- 
mechanical treatment to estimate bulk modulus for solids.

\section{Theory}

o calculate thermodynamic functions of state we applied the canonical ensemble ${ }^{24-25}$. Utilizing the semiclassical formulation for the purpose of the canonical ensemble for the $N$ indistinguishable molecules, the partition function $\mathrm{Z}$ can be expressed as follows ${ }^{15}$ :

$Z=\frac{1}{N ! h^{S N}} \int \ldots . . \int \exp \left(-\frac{H}{k T}\right) \cdot d \vec{r}_{1} d \vec{r}_{2} \ldots \ldots d \vec{r}_{N} d \vec{p}_{1} d \vec{p}_{2} \ldots . . d \vec{p}_{N},(1)$ where $S$ - stands for the number of degrees of freedom of individual molecules, $H$ - designates the Hamiltonian molecule system, vectors $\vec{r}_{1} \vec{r}_{2} \ldots . . \vec{r}_{N}$ describes the positions of $N$ molecules and $\vec{p}_{1} \vec{p}_{2} \ldots \ldots \vec{p}_{N}$ indicates their linear conjugate momentums, $k$ and $h$ Boltzmann's and Planck's constants, respectively.

In the canonical ensemble, the equation of state is given by [15]:

$$
P=k T\left(\frac{\partial \ln Z}{\partial V}\right)_{T, N},
$$

where $T$ is the temperature and $V$ is the volume of molecular system.

Our thermodynamic system consists of $N$ particles associated by attractive forces. Atoms in their crystal lattices are not motionless but they oscillate thermally near their equilibrium positions. This assembly of atoms has $3 N-6$ vibration degrees of freedom (One can ignores the number of translational and rotational degrees of freedom in comparison to the total normal mode of vibrations because the number of later is so large in solids). [26]:

Henceforth, the canonical partition function is given

$$
Z=\left[\frac{\exp \left(-\Theta_{D} / 2 T\right)}{1-\exp \left(-\Theta_{D} / T\right)}\right]^{3 N}
$$

where $\Theta_{D}$ is Debye characteristic temperature. The Debye model of solids treats a solid as an isotropic elastic substance ${ }^{26}$. Using the canonical partition function, the above relation could be cast into [26]

$$
\ln Z=-\frac{9}{8} N \frac{\theta_{D}}{T}-3 N \operatorname{Ln}\left(1-\exp \left(-\frac{\theta_{D}}{T}\right)+3 N\left(\frac{T}{\theta_{D}}\right)^{3} \int_{0}^{\frac{\theta_{D}}{T}} \frac{\xi^{3}}{\exp (\xi)-1} d \xi\right.
$$

The Debye characteristic temperature will be determined by means of Gruneisen parameter $\gamma$ [27-28]:

$$
\gamma(\rho) \equiv \frac{d \ln \theta_{D}}{d \ln \rho}
$$

where $\rho$ is the density. We have fitted the Gruneisen parameter 28-29] with density [30]. Our typical result for iron is as follows:

$$
\gamma(\rho)=a+b \rho+c \rho^{2}
$$

where $\mathrm{a}=2.966051, \mathrm{~b}=-0.1841206$, and $\mathrm{c}=$ 0.004033906. Finding the Debye characteristic temperature from Gruneisen parameter by means of Eq. (5) gives the following expression:

$$
\theta_{D}=d \rho^{a} \exp \left(b \rho+c \rho^{2}\right),
$$

where $\mathrm{d}=2.754820453$.

On the other hand, Eq. (2) can be re-arranged as:

$$
P=-k T \rho^{2}\left(\frac{\partial \ln Z}{\partial \rho}\right)_{T, N}
$$

This is the key equation that we acquired in our mathematical model for the calculation of bulk modulus in solid crystals. In continuation, we are going to focus on the bulk modulus, $B_{T}$, the inversion of the isothermal compressibility factor, $\kappa_{T}$, as follows:

$$
B_{T} \equiv \frac{1}{\kappa_{T}}=-V\left(\frac{\partial P}{\partial V}\right)_{T, N},
$$

From Eq. (9) with a simple algebra one can find the following equation:

$$
B_{T}=\rho\left(\frac{\partial P}{\partial \rho}\right)_{T, N},
$$

The aforementioned equation is the central part of our procedure for estimating the bulk modulus of solids based on the statistical-mechanical treatment.

\section{Results and Discussion}

Knowing the density dependence of Gruneisen parameter on the one hand and the utilization of the basic statistical-mechanical relation on the other hand enables us to compute the bulk modulus of solids with reasonable accuracy. Apart from such applications of the present theoretical approach, the statistical-mechanically-based formula of bulk modulus presented in this work is also significant in elucidating the molecular model for thermophysical properties of solids. Another significant importance of the proposed relation is its obvious linkage to the microscopic characteristic features of concerned solids from the statistical- mechanical viewpoint [31-32].

Therefore, the problem of deriving an analytical expression for thermophysical properties of fluids and solids has remained an important problem in the field of thermodynamics [33-34]. By proposing the definition of canonical partition function from statistical mechanics, i.e. Eq. (1) and its refinement according to Debye model of solids in the first step, i.e. Eq. (4), and the insertion of this outcome in the purely statistical-mechanical relation for pressure, i.e. Eq. (2), in the second step, are admitted, 
The First Principle Approach in Estimating Bulk Modulus Based...

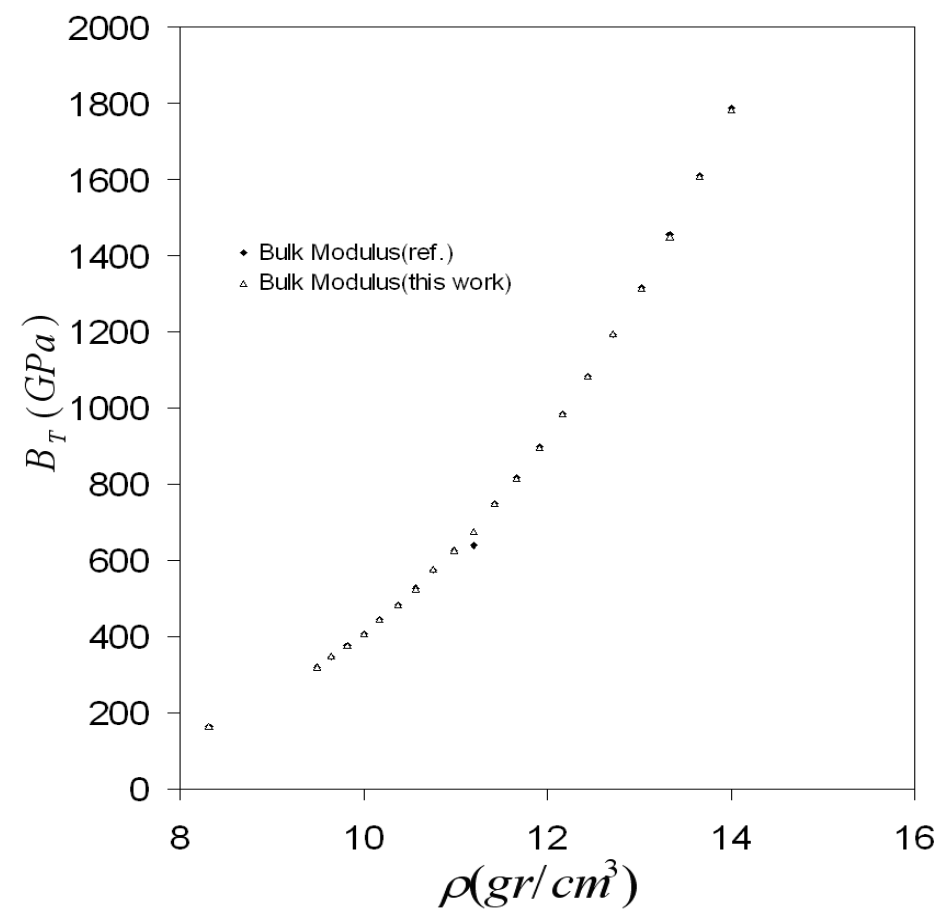

Fig. 1. Bulk modulus of iron (hcp) at $300 \mathrm{~K}$ as a function of density $\left(\mathrm{g} / \mathrm{cm}^{3}\right)$. ( $\left.\bullet\right)$ is the experimental value [Ref.35] and $(\Delta)$ is the calculated one.

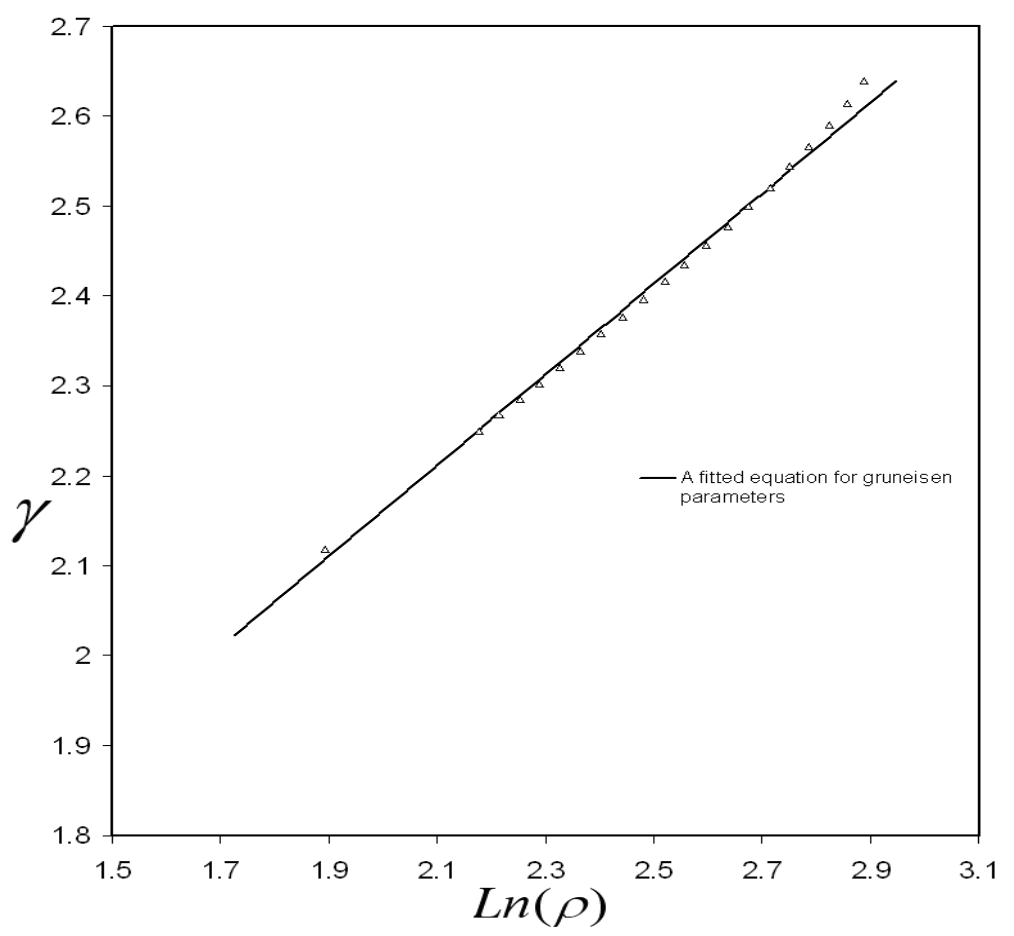

Fig. 2. Gruneisen Parameters $(\gamma(\rho))$ of iron (hcp) at $300 \mathrm{~K}$ as a function of $\operatorname{Ln}(\rho)$.

we are able to derive an expression for pressure in terms of Debye characteristic temperature. Due to exactness of our results we are able to manipulate Eq. (8) in conjunction with bulk modulus, i.e. Eq. (10). By adopting the density dependence of Debye characteristic temperature (by defining Gruneisen parameter) which has been introduced by Anderson ${ }^{27-28,35}$, i.e. Eq. (5), we deduced the closed-form for Debye characteristic temperature in terms of density for hcp iron, i.e. Eq. (7). It should also be notified that for this purpose we are determined to fit Gruneisen parameter with density, i.e. Eq. (6).

The paper presents the mathematical model for computation of thermodynamic properties, especially the 
Table 1

The connection between our outcomes and Anderson et al. (35)

\begin{tabular}{|c|c|c|c|c|c|}
\hline $\mathrm{Y}^{* 10}$ & $\mathrm{~V}\left(\mathrm{~cm}^{3} \mathrm{~mole}^{-1}\right)$ & $\rho\left(\mathrm{g} \mathrm{cm}^{-3}\right)$ & $\Theta_{\mathrm{D}}(\mathrm{K})$ & $\mathrm{B}_{\mathrm{T}}$ (this work $)$ & $\mathrm{B}_{\mathrm{T}}$ (reference) \\
\hline 1.85 & 6.73 & 8.321 & 422 & 163.9 & 164 \\
\hline 2.2 & 5.9 & 9.491 & 524 & 318.82 & 318.8 \\
\hline 2.24 & 5.8 & 9.655 & 539 & 347.33 & 346.1 \\
\hline 2.27 & 5.7 & 9.825 & 554 & 375.34 & 375.8 \\
\hline 2.31 & 5.6 & 10 & 569 & 408.94 & 408.3 \\
\hline 2.34 & 5.5 & 10.18 & 585 & 442.92 & 444 \\
\hline 2.37 & 5.4 & 10.37 & 602 & 482.5 & 483.2 \\
\hline 2.41 & 5.3 & 10.566 & 618 & 525.05 & 526.2 \\
\hline 2.45 & 5.2 & 10.77 & 636 & 575.62 & 573.7 \\
\hline 2.48 & 5.1 & 10.98 & 654 & 625.79 & 625 \\
\hline 2.51 & 5 & 11.2 & 673 & 695.91 & 638.8 \\
\hline 2.55 & 4.9 & 11.42 & 692 & 747.15 & 747.8 \\
\hline 2.58 & 4.8 & 11.667 & 712 & 815.27 & 818.9 \\
\hline 2.62 & 4.7 & 11.915 & 733 & 896.73 & 897.8 \\
\hline 2.66 & 4.6 & 12.174 & 754 & 985.43 & 985.7 \\
\hline 2.7 & 4.5 & 12.444 & 776 & 1084.05 & 1083.8 \\
\hline 2.74 & 4.4 & 12.727 & 799 & 1193.77 & 1193.5 \\
\hline 2.78 & 4.3 & 13.023 & 822 & 1313.19 & 1316.6 \\
\hline 2.82 & 4.2 & 13.333 & 847 & 1448.42 & 1454.9 \\
\hline 2.87 & 4.1 & 13.658 & 872 & 1606.54 & 1610.7 \\
\hline 2.92 & 4 & 14 & 898 & 1782.8 & 1786.8 \\
\hline
\end{tabular}

bulk modulus, for pure solids. At the first glance, our analytical results are compared with the experimental data of iron. In Fig. 1 curve of bulk modulus has been graphed versus density. We have confined ourselves to the available experimental values which have been reported by Anderson et al. [35]. The scarcity of experimental data is the main reason of limitation in our calculations on bulk modulus. Despite lack of the experimental data, there is reasonable correctness in our computational method. We performed calculations exactly on the available experimental data datum by datum. As may be observed, there is one datum below the $9 \mathrm{~g} / \mathrm{cm}^{3}$. It seems that beyond this density an adequate accordance is observed and there are insignificant deviations which are below $12 \mathrm{~g} / \mathrm{cm}^{3}$ but the overall or correspondence is fairly good. The density dependence of the Gruneisen parameter is illustrated in Figure 2. The original idea for choosing the temperature as $300 \mathrm{~K}$ to fit the value of $\gamma(\rho)$ for iron (hcp) has been the existence of relevant data in order to check our theoretical outcomes by the experimental data. As we expected according to Eq. (6), which has been fitted in the present work, it is obvious that $\gamma(\rho)$ decayed as the density increased. The lack of calculated data between 8 $\mathrm{g} / \mathrm{cm}^{3}$ and $10 \mathrm{~g} / \mathrm{cm}^{3}$ are due to un-availability of pertinent isothermal compressibility factor datum. It must be mentioned that for executing our procedure we seriously need the closed-form for density dependency of Debye characteristic temperature. For this purpose we utilized the definition of Gruneisen parameter. It should also be notified that the scarcity of data ${ }^{36-37}$ forced us to estimate $\gamma(\rho)$ for iron (hcp) by fitting the data which ultimately corresponds to the latest result of isothermal compressibility factor datum. The calculated values of Debye temperature of iron (hcp) at $300 \mathrm{~K}$ as a function of density is illustrated in Fig. 3. As it is apparent from Fig. 3 linear increase in density against Debye characteristic temperature is expected as we used Eq. (7) to acquire density variations of Debye characteristic temperature. Indeed our graph is the exact illustration of Eq. (7). It is worthy to note that the $a, b$ and $c$ coefficients are exactly the same as in Eq. (6).

In Table I the connection was made between our outcomes and Anderson et al. results [35]. It should also be mentioned that the inverse of isothermal compressibility factor gives the value of bulk modulus according to Eq. (9).

Despite little discrepancy of data with respect to 
The First Principle Approach in Estimating Bulk Modulus Based...

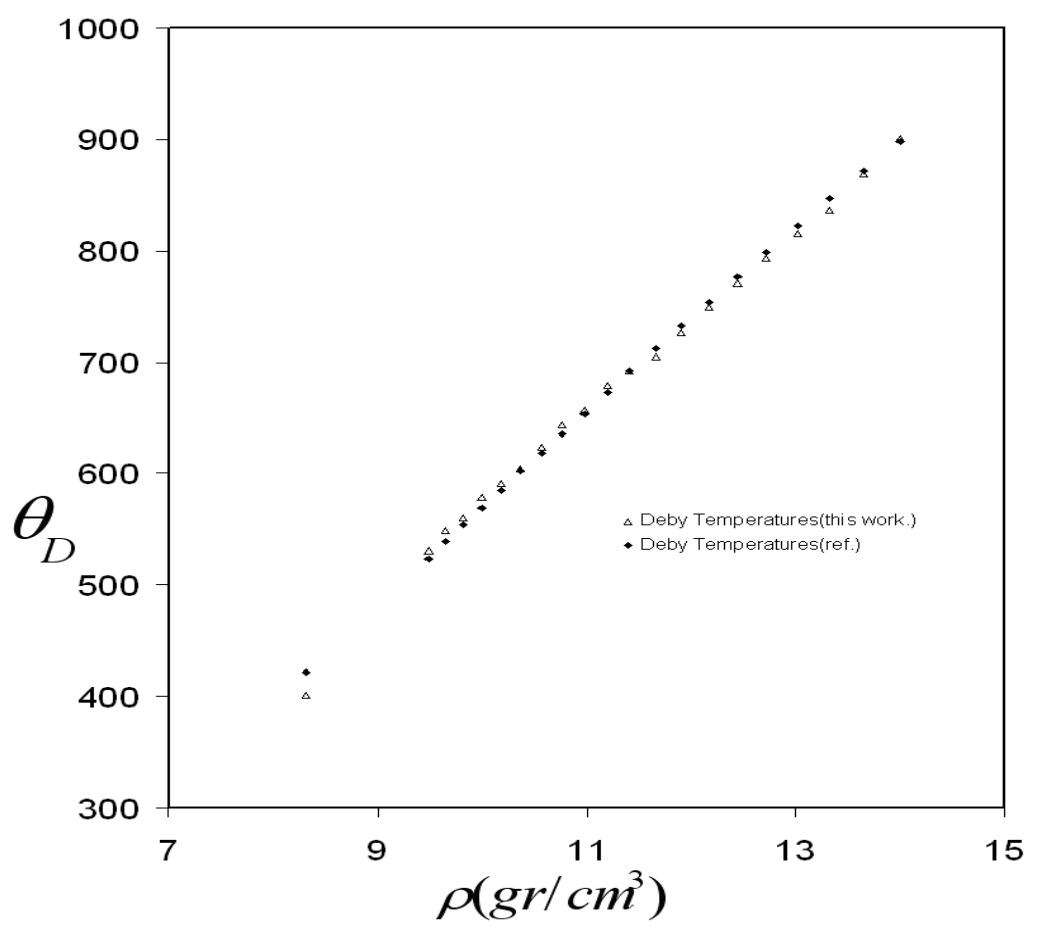

Fig. 3. Calculated values of Debye temperature of iron (hcp) at $300 \mathrm{~K}$ as a function of density. ( $\downarrow)$ is the experimental value [35] and $(\Delta)$ is the calculated one.

Anderson et al. data [35], we believe that the main reason might be the multiple fitting which caused these discrepancies. In general, there are few available data on Gruneisen parameter or on the Debye characteristic temperature (especially its density dependency) in the literature, so it seems wise for us to have some deviations from calculated bulk modulus (or isothermal compressibility factor) with experimental one [37].

\section{Conclusions}

The present method is able to predict the bulk modulus of solids over a wide range of density. Only one scaling constant, the Gruneisen parameter, $\gamma(\rho)$ in this case is needed. We believe that our method can be utilized in its usual form exactly because the present framework has been reinforced by using the wellestablished analytical equation of statistical physics. In our work, we used the experimental data for iron to fit Gruneisen parameter, $\gamma(\rho)$ as a function of the density. Moreover, it should be emphasized that we do not need the large assembly of input data for executing the procedure. This is a very important advantage compared to the other estimation methods [22-23, 38-39].

By paying meticulous attention to details of the other proposed methods for predicting the bulk modulus for solids which are specific for a narrow range of density, it seems wise to clarify that the unique novelty of the present work is to predict bulk modulus at high-density regime and to calculate with simplicity and reasonable accuracy the bulk modulus for solid crystals knowing $\gamma(\rho)$ (only input) as a function of density at any desirable ranges. Additionally, the present work demonstrates a microscopic recipe of calculation of bulk modulus based on statistical-mechanical treatment producing reliable information.

\section{Acknowledgement}

We are much indebted to Prof. A. Maghari for his generous encouragement, his provocative insights, and many enticing vistas opened up by his classic studies of statistical mechanics (both equilibrium and nonequilibrium).

Hojjat Mangelli - MSc. Student of Department of Physics;

Majid Vafaeei - Lecturer of Department of Chemistry; Nader Mansoori Oghaz - Lecturer of Department of Education;

Behzad Haghighi - Lecturer of Department of Chemistry.

[1] B. Haghighi, A. Hassani Djavanmardi, M. Najafi and M.M. Papari, J. Theor. \& Comput. Chem., 2, 371 (2003) (https://doi.org/10.1142/S0219633603000689).

[2] B. Haghighi, A. Hassani Djavanmardi, M.M. Papari and M. Najafi, J. Theor. \& Comput. Chem., 4, 69 (2004) (https://doi.org/10.1142/S021963360400091X).

[3] J. Moghadasi Absardi, M.M. Papari, L. Mohammad-Aghaie and B. Haghighi, Bull. Chem. Soc. Japan, 81, 1219 (2008). 
[4] A.E. Nasrabad, N. Mansoori Oghaz and B. Haghighi, J. Chem. Phys., 129, 024507 (2008) (https://doi.org/10.1063/1.2953331).

[5] N. Mansoori Oghaz, D. Shahidi, E. Ghiamati and B. Haghighi, Chem. Phys., 369, 59 (2010) (https://doi.org/10.1016/j.chemphys.2010.02.003).

[6] N.M. Oghaz, E. Ghiamati, B. Haghighi, A.E. Nasrabad, M.M. Papari and M. Bamdad, J. Mol. Liq., 165, 55 (2012) (https://doi.org/10.1016/j.molliq.2011.10.008).

[7] M.M. Papari, S. Amighi, M. Kiani, D. Mohammad-Aghaie and B. Haghighi, J. Mol. Liq., 175, 61 (2012) (https://doi.org/10.1016/j.molliq.2012.08.013).

[8] N. Mansoori Oghaz, B. Haghighi, M. M. Alavianmehr and E. Ghiamati, J. Sol. Chem. 42 , 54 (2013) (https://doi.org/10.1021/jp044393q).

[9] M. M. Alavianmehr , S. M. Hosseini , B. Haghighi and J. Moghadasi, Chem. Eng. Sci. 122, 622 (2015) (https://doi.org/10.1016/j.ces.2014.10.009).

[10] M. M. Papari, D. Mohammad-Aghaie, B. Haghighi and A. Boushehri, Fluid Phase Equil 232, 122 (2005) (https://doi.org/10.1016/j.fluid.2005.03.022).M. Kardar, Statistical Physics of particles (Cambridge University press, 2007).

[11] M. Kardar, Statistical Physics of fields (Cambridge University press, 2007).

[12] J.M. Prausnitz, R.N. Litchtenthaler and E.G. de Azevedo, Moleular Thermodynamics of Fluid-Phase Equilibria, Third Edition (Prentice Hall, New Jersey, 1999).

[13] B.C. Eu, Generalized Thermodynamics: The Thermodynamics of Irreversible Processes and Generalized Hydrodynamics (Kluwer, Dordrecht, 2002).

[14] D.A. McQuarrie, Statistical Mechanics (Harper \& Row, New York, 1976).

[15] T. Padamanabhan, Phys. Rep. 188, 285 (1990) (https://doi.org/10.1016/0370-1573(90)90051-3).

[16] E. Ziambaras and E. Schroder, Phys. Rev. B, 68, 064112 (https://doi.org/10.1103/PhysRevB.68.064112).

[17] Singh P K, Indian J Pure \& App Phys. 49, 829 (2011).

[18] G. I. Cui, R. I. Yu and L. R. Chen, Physica B 348, 404 (2004) (https://doi.org/10.1016/j.physb.2004.01.003).

[19] J. Garai and A. Laugier, J. App. Phys. 101, 023514 (2007) (https://doi.org/10.1016/j.physb.2004.01.003).

[20] B.P. Singh and S.K. Srivastava and K. Dinesh, Physica B 349, 401 (2004) (https://doi.org/10.1016/j.physb.2003.12.020).

[21] M. Kumar, Physica B, 365, 1 (2005) (https://doi.org/10.1016/j.physb.2005.04.007).

[22] M.L. Klein, Ann. Rev. Phys. Chem. 36, 525 (1985) (https://doi.org/10.1146/annurev.pc.36.100185.002521).

[23] S.K. Ma, Statistical Mechanics (World Scientific, Philadelphia, 1985).

[24] F.J. Pierce, Microscopic Thermodynamics (International Textbook Company, Pennsylvania, 1966).

[25] J. Avsec and M. Oblak, Int. J. Heat \& Mass Transfer 50, 4331 (2007) (https://doi.org/10.1016/j.ijheatmasstransfer.2007.01.064).

[26] O.L. Anderson, Equation of States for Geophysics and Ceramic Science (Oxford University Press, New York, 1995).

[27] O. L. Anderson, Geophys. J. Int. 143, 279 (2000) (https://doi.org/10.1046/j.1365-246X.2000.01266.x).

[28] J. Shanker, B. P. Singh and H. K. Baghel, Physica B 387, 409 (https://doi.org/10.1016/j.physb.2006.04.026)

[29] L. Burakovsky and D. L. Preston, J. Phys. Chem. Solids 65, 1581 (2004) (https://doi.org/10.1016/j.jpcs.2003.10.076).

[30] A. C. Holt and M. Ross, Phys Rev B 1, 2700 (1970) (https://doi.org/10.1103/PhysRevB.1.2700).

[31] N.L. Vocadlo and G.D. Price, Phys. Earth Planet Int. 82,261 (1994).

[32] A. Sparavigna, Phys. Rev. B, 56, 7775 (1997) (https://doi.org/10.1103/PhysRevB.56.7775).

[33] S. S. Kushwash, Phys. Earth Planet Int. 149, 201 (2005) (https://doi.org/10.1016/j.pepi.2004.09.010).

[34] O.L. Anderson, D.G.Isaak and V.E. Nelson, J. Phys. Chem. Solids 64, 2125 (2003) (https://doi.org/10.1016/S0022-3697(03)00112-4).

[35] E.G. Moroni and T. Jarlborg, Europhys. Lett. 33, 223 (1996) (https://doi.org/10.1209/epl/i1996-00324-1).

[36] G. Steinle-Neumann and L. Stixrude, Phys. Rev. B, 60, 791(1999) (https://doi.org/10.1103/PhysRevB.60.791).

[37] K. Sushil, Physica B, 367, 114 (2005) (https://doi.org/10.1016/j.physb.2005.06.004).

[38] X.C. Peng, L.I. Xing and Z.H. Fang, Physica B, 394, 111 (2007) (https://doi.org/10.1103/PhysRevB.68.064112). 


\section{Х. Мангеллі ${ }^{1}$, М. Вафаей${ }^{1}$ Н. Мансурі Огхаз ${ }^{2}$ Б. Хаггіхі ${ }^{1}$}

\section{Застосування розрахунків з перших принципів для оцінки об'ємного модуля на основі явного вираження канонічної функції розподілу}

\footnotetext{
${ }^{1}$ Університет Нейшабур, Нейшабур, провіниія Разаві Хорасан, Іран, е-таil: Hojjat.mangeli67@gmail.com ${ }^{1}$ Фархангійський університет, Бойнорд, провінція Північний Хорасан, Iран, e-mail: Haghighi.behzad@gmail.com

Об’ємний модуль є однією із найважливіших характерних твердих тіл. У статті розроблено статистико-механічну обробку на основі рівняння, що дозволяє обчислити об'ємний модуль для твердих тіл із мінімальною кількістю початкових даних. У запропонованій моделі встановлено взаємозв'язок між параметром Грюнайзена і канонічною функцією розподілу. Показано, що об'ємна залежність параметра Gruneisen $€$ критичною при оцінці об'ємного модуля. Результати для гексагонального щільно упакованого заліза показали дуже добре узгодження із експериментом. Таке наближення можна екстраполювати і для інших елементарних твердих тіл чи різних сполук.

Ключові слова: об’ємний модуль, канонічна функція розподілу, густина, параметр Грюнайзена, статистична механіка.
} 